\title{
Knee pain and osteoarthritis in older adults: a review of community burden and current use of primary health care
}

\author{
G Peat, R McCarney, P Croft
}

\begin{abstract}
Background-Osteoarthritis is the single most common cause of disability in older adults, and most patients with the condition will be managed in the community and primary care.

Aim-To discuss case definition of knee osteoarthritis for primary care and to summarise the burden of the condition in the community and related use of primary health care in the United Kingdom.

Design-Narrative review.

Method-A literature search identified studies of incidence and prevalence of knee pain, disability, and radiographic osteoarthritis in the general population, and data related to primary care consultations. Findings from UK studies were summarised with reference to European and international studies.
\end{abstract}

Results-During a one year period $25 \%$ of people over 55 years have a persistent episode of knee pain, of whom about one in six in the UK and the Netherlands consult their general practitioner about it in the same time period. The prevalence of painful disabling knee osteoarthritis in people over 55 years is $10 \%$, of whom one quarter are severely disabled.

Conclusion-Knee osteoarthritis sufficiently severe to consider joint replacement represents a minority of all knee pain and disability suffered by older people. Healthcare provision in primary care needs to focus on this broader group to impact on community levels of pain and disability.

(Ann Rheum Dis 2001;60:91-97)

Primary Care Scienc

Research Centre,

Keele University, UK

G Peat

R McCarney

P Croft

Correspondence to:

Dr G Peat, Primary Care

Sciences Research Centre,

School of Postgraduate

Medicine, Keele University,

The Medical Institute,

Hartshill Road,

Stoke-on-Trent ST7 4NY,

UK

g.m.peat@hfac.keele.ac.uk

Accepted 25 July 2000 care will ignore the majority of people with the condition in question. Such assessments need to embrace problems as they present in primary care and the health care available in that setting.

Osteoarthritis represents a particularly strong argument for a primary care perspective on needs assessment. It is the second most common diagnosis made in older people consulting their general practitioner, ${ }^{2}$ and the commonest cause of disability at older ages. ${ }^{3}$ Furthermore, Lane and Thompson, in an evidence based review, ${ }^{4}$ have identified a range of primary care interventions (both pharmacological and non-pharmacological) which have some evidence of effectiveness for patients with osteoarthritis.

This paper is concerned with knee osteoarthritis and its objective is to consider three other areas required to complete a United Kingdom primary care health needs assessment: defining the condition for primary care, its prevalence in the general population (community burden), and the proportion with the condition who might currently present to primary care (use of health care). The burden represents the total pool of potential need for health care, whereas the pattern of healthcare use reflects current demand for that health care.

Throughout the paper we have endeavoured to summarise results from studies conducted in the United Kingdom and to contrast these with estimates from similar European and international studies.

We consider first how to define the problem at a community and primary care level.

Defining osteoarthritis: pain, disability, or radiography?

Osteoarthritis of the knee is an active disease process involving cartilage destruction, subchondral bone thickening, and new bone formation. Radiographic appearance has traditionally been the cornerstone of diagnosis because the effects of the pathological processes can be identified as features on the $x$ ray: joint space narrowing, subchondral sclerosis, and osteophyte formation. The radiographic changes can be classified according to their location within the joint (the two tibiofemoral joint compartments and the patellofemoral joint) and their severity.

Up to a third of older adults in the general population show radiological evidence of knee 
osteoarthritis and this is strongly age related..$^{5-9}$ Two findings from population surveys, however, illustrate why a distinction must be made between the radiographic and the clinical syndromes. Firstly, $50 \%$ of subjects in the general population with radiographic knee osteoarthritis do not have pain. Secondly, $50 \%$ of subjects who complain of knee pain, and who are at or above the age when osteoarthritis starts to become common (about 55 years), have no definite radiographic evidence of osteoarthritis. $^{10}$

The choice between radiographic and clinical case definitions will depend on how they are to be applied. Investigations of the causes of osteoarthritis can focus on radiographic criteria, regardless of symptoms. The underlying assumption is that if the pathological process which gives rise to the $x$ ray changes could be averted or slowed down this would be one means of preventing pain and disability. By contrast, any attempt to assess needs and options for health care in patients with established radiographic knee osteoarthritis must focus on the associated symptoms and disability. Guidelines published by the American College of Rheumatology provide for the classification of osteoarthritis as a clinical syndrome in older adults who present with knee pain, morning stiffness, and joint crepitus. ${ }^{11}{ }^{12}$ Although its shortcomings are recognised, ${ }^{13}$ this classification of knee osteoarthritis probably reflects accepted clinical practice, ${ }^{14}$ but at present there is no evidence on how the label of osteoarthritis is actually assigned in practice. In a Canadian study $25 \%$ of patients being managed as knee osteoarthritis had normal radiographs. ${ }^{15}$ Prospective cohort data suggest that radiographic change may not be strongly related to clinical outcome, ${ }^{16}$ and current primary care guidelines regard $x$ rays as non-essential for diagnosis and management. ${ }^{17}$ Pain and disability are the main presenting features and the targets of primary care management.

An estimate of the population burden of knee osteoarthritis in older adults might then reasonably take as its starting point the presenting symptom of "knee pain". Diagnosis is helped by age grouping. Below the age of 55, there are more common causes of knee pain than osteoarthritis - notably, injuries to cartilage, ligaments, and soft tissue structures around the joint. Such injuries may predispose to later osteoarthritis and be relevant to the primary prevention of knee osteoarthritis. Above the age of 55, radiographic knee osteoarthritis is an increasingly common cause of knee pain. ${ }^{18} 19$
From this starting point, this paper considers two questions regarding a population based assessment of the burden of knee osteoarthritis and related use of primary health care. Firstly, how common is knee pain and associated disability in older adults living in the community, and what proportion can be expected to have radiographic evidence of osteoarthritis? Secondly, what is the associated prevalence and incidence of primary care consultations?

\section{Prevalence and incidence of knee pain, disability, and radiographic osteoarthritis in registered practice populations} SEARCH STRATEGY

A Medline search was conducted to identify original studies reporting estimates of population prevalence and/or incidence of knee pain and knee osteoarthritis in older patients (period: 1966-98; language: English). The appendix gives the search strategy and keywords.

Several high quality surveys of the occurrence of knee pain and osteoarthritis conducted in United Kingdom populations were identified. We have chosen to summarise these findings and to use estimates from other European and international studies for comparison. In reviewing evidence on consultations for knee pain and osteoarthritis, greater consideration was given to European and North American studies because of relatively sparse UK data.

PREVALENCE OF KNEE PAIN

Although most general pain surveys in the population have not separately considered knee pain or clearly defined it, a number of studies in the United Kingdom have estimated the prevalence of knee pain in older adults. Table 1 shows the findings from these surveys.

Two surveys specifically concerning knee pain in older adults, conducted in Bristol ${ }^{19}$ and Nottingham ${ }^{20}$ both estimated an annual prevalence of $25 \%$ for knee pain in older adults. This is consistent with a more recent survey of musculoskeletal disorders in Tameside, Greater Manchester, which found a prevalence of knee pain that lasted for at least a week in the previous month of between $21 \%$ and $35 \%$ in men and women aged 45 or over. ${ }^{21}$ Two other UK studies-from Chingford ${ }^{8}$ and Calderdale ${ }^{22}$ together with surveys conducted in the United States ${ }^{523}$ and the Netherlands, ${ }^{79}$ have tended to yield lower estimates of the prevalence of knee pain in older adults. Variation in case definitions, the composition of study groups, whether the method was postal or interview, and the inclusion of questions about other pain sites may explain these differences. ${ }^{25}$

Table 1 Prevalence of knee pain in older adults

\begin{tabular}{|c|c|c|c|}
\hline Study location & Sample & Case definition & $\begin{array}{l}\text { Overall } \\
\text { prevalence } \\
\text { estimate (\%) }\end{array}$ \\
\hline Chingford, England $^{8}$ & F aged $45-65(n=400)$ & $\begin{array}{l}\text { Knee pain at any time in the past month } \\
\text { Knee pain for most days in the past month }\end{array}$ & $\begin{array}{l}13 \text { approx } \\
6.5\end{array}$ \\
\hline Calderdale, England ${ }^{22}$ & $M+F$ aged $55+$ resident in Calderdale $(n=15150)$ & Current knee joint problems (time period unspecified) & 19 \\
\hline Bristol, England ${ }^{19}$ & $M+F$ aged over 55 registered at one general practice $(n=2102)$ & $\begin{array}{l}\text { Ever had knee pain on most days for at least a month }+ \\
\text { knee pain in past year }\end{array}$ & 25 \\
\hline Nottingham, England ${ }^{20}$ & $M+F$ aged $40-79$ registered at two general practices $(n=4057)$ & Knee pain in the past year on most days for at least a month & 25 \\
\hline Tameside, England ${ }^{21}$ & $M+F$ aged $45+$ registered at three general practices $(n=4349)$ & Knee pain for more than one week in the past month & 28 \\
\hline
\end{tabular}


Table 2 Prevalence of symptomatic radiographic knee osteoarthritis in older adults

\begin{tabular}{lll}
\hline Study location & Sample & Case definition \\
\hline Bristol, England $^{10}$ & $\mathrm{M}+\mathrm{F}$ aged over 55 registered at one general practice $(\mathrm{n}=513)$ & $\begin{array}{l}\text { Overall } \\
\text { prevalence } \\
\text { estimate (\%) }\end{array}$ \\
Nottingham, England ${ }^{20}$ & $\mathrm{M}+\mathrm{F}$ aged $40-79$ registered at two general practices $(\mathrm{n}=459)$ & $\begin{array}{l}\text { Knee pain }+ \text { grade } 1+\text { osteophytes } \\
\text { Knee pain }+ \text { grade 2+ osteophytes }\end{array}$ \\
\hline
\end{tabular}

When allowance is made for variations in definition, knee pain in older adults is common the world over. In one population based survey of Chinese subjects aged 70 and over, the knee was the most commonly reported site of pain complaints, ${ }^{26}$ supporting similar observations in European countries. ${ }^{2122}$ The prevalence of knee pain increases universally with age, though age trends are clearer in women than men.

PREVALENCE OF KNEE PAIN WITH RADIOGRAPHIC OSTEOARTHRITIS

The Bristol and Nottingham studies ${ }^{19}{ }^{20}$ examined the prevalence of radiographic osteoarthritis in older adults with knee pain (table 2).

Estimates of $5 \%$ to $15 \%$ have been reported in surveys undertaken in other countries. ${ }^{79242829}$ The highest estimate has been an American survey of a rural population, which found a prevalence of $38 \%$ for definite radiographic knee osteoarthritis. ${ }^{30}$ Sun and colleagues, in a wide ranging review of population prevalence studies in the literature, highlighted the impact of variations in study design, study group, and case definition on these estimates. ${ }^{31}$

Most of the variation is attributable to differences in estimating the total prevalence of pain rather than in the proportion of this group who demonstrate radiographic changes. When the age related influence on prevalence is taken into account, the figures for symptomatic radiographic osteoarthritis are remarkably consistent across different studies.

With the exception of the Calderdale study, prevalence estimates of knee pain from UK surveys are unlikely to include cases of transient episodes of pain that would imply minimal or no need for primary health care. Nevertheless, knee pain of longer duration, even when accompanied by radiographic features of osteoarthritis, is not always associated with significant impact upon people's lives. To arrive at a clearer understanding of health needs associated with knee pain which are rel- evant to the provision of primary care services it is necessary to consider the group of patients in whom disability is also present.

PREVALENCE OF KNEE PAIN AND DISABILITY

In studies specifically focused on the knee, at least half of all older adults with knee pain report some restriction of daily activity (table $3)$.

There is relatively good agreement between UK studies on the prevalence of "knee pain with some associated disability" in older adults. Figures from the Bristol study suggest that $15 \%$ of subjects in the general population aged over 55 have had restricted activity because of knee pain occurring on most days in one month during the past year. ${ }^{19}$ In the Nottingham study of $40-79$ year olds, $14 \%$ of subjects had had knee pain with disability on most days of the previous month. ${ }^{20}$ These estimates fall within the range found in the Tameside study. ${ }^{21}$ In a population survey of 16191 people aged 55 and over in the north of England, the prevalence of knee problems which had lasted for more than six weeks in the previous three months and which were associated with some difficulty in everyday living was $8 \% .^{32}$ This figure was age related, so that it was lower if younger adults were included, and higher when older subgroups were considered separately.

The north of England study further classified these estimates according to the degree of pain and disability. Subjects who reported pain and disability were asked to complete the Lequesne index of severity developed for knee osteoarthritis. The prevalence of pain and disability scoring 14 points or more on the Lequesne index (extremely severe knee pain and disability ${ }^{33}$ ) was $1.3 \%$ at age $55-64$ years, $1.6 \%$ at $65-74$ years, and $3.5 \%$ at 75 and over. Over 65 years, the prevalence of such severe problems was twice as common in women as in men.

Table 3 Prevalence of knee pain and disability in older adults

\begin{tabular}{|c|c|c|c|}
\hline Study location & Sample & Case definition & $\begin{array}{l}\text { Overall } \\
\text { prevalence } \\
\text { estimate (\%) }\end{array}$ \\
\hline Bristol, England ${ }^{19}$ & $M+F$ aged over 55 registered at one general practice $(n=2102)$ & $\begin{array}{l}\text { Knee pain }+ \text { HAQ }>0 \\
\text { ("any disability") }\end{array}$ & $15^{\star}$ \\
\hline North Yorks, England ${ }^{32}$ & $M+F$ aged $55+$ resident in $N$ Yorks Health Authority $(n=16$ 191) & $\begin{array}{l}\text { Knee pain causing problems for more } \\
\text { than } 6 \text { weeks in the past } 3 \text { months } \\
\text { Knee pain + Lequesne }>14 \\
\text { ("extremely severe pain and disability") } \\
\text { Knee pain + Lequesne }>20 \\
\text { ("extreme pain and disability") }\end{array}$ & $\begin{array}{l}8 \\
1.6 \\
0.4\end{array}$ \\
\hline Nottingham, England ${ }^{20}$ & $M+F$ aged $40-79$ registered at two general practices $(n=4057)$ & $\begin{array}{l}\text { Knee pain }+ \text { SF- } 36 \text { physical function scale } \\
\text { in lowest tertile for total population }\end{array}$ & 14 \\
\hline Tameside, England ${ }^{21}$ & $M+F$ aged $45+$ registered at three general practices $(n=4349)$ & $\begin{array}{l}\text { Knee pain + MHAQ† }>0 \\
\text { ("some disability") }\end{array}$ & 15 \\
\hline
\end{tabular}

${ }^{\star}$ Calculated using approximate figures from graphic display of data.

$+\mathrm{HAQ}=$ Health Assessment Questionnaire; $\mathrm{MHAQ}=$ modified HAQ . 
Table 4 Prevalence of knee pain and disability with radiographic osteoarthritis in older adults, United Kingdom

\begin{tabular}{llll}
\hline Study location & Sample & Case definition & $\begin{array}{l}\text { Overall } \\
\text { prevalence } \\
\text { estimate (\%) }\end{array}$ \\
\hline Bristol, England $^{10}$ & $\begin{array}{l}\mathrm{M}+\mathrm{F} \text { aged over 55 registered at one } \\
\text { general practice (n=513) }\end{array}$ & $\begin{array}{l}\text { Knee pain + HAQ } \\
\text { ("any disability") + radiographic OA }\end{array}$ & 7.5 \\
\hline
\end{tabular}

${ }^{\star} \mathrm{HAQ}=$ Health Assessment Questionnaire.

PREVALENCE OF KNEE PAIN AND DISABILITY WITH RADIOGRAPHIC OSTEOARTHRITIS

Clinicians found the north of England study controversial because it extrapolated from self reported knee pain and disability to estimates of the need for knee replacement surgery. ${ }^{32}$ The controversy lay in the fact that no clinical or radiological assessment was carried out. The Bristol study ${ }^{1019}$ used a different disability measure (the Health Assessment Questionnaire (HAQ)). Unlike the Lequesne instrument employed in the north of England study, the HAQ is not knee-specific, but the Bristol study was able to provide an estimate of " $k$ nee pain associated with disability in daily living and with radiographic change": $12.5 \%$ of adults aged over 55 had knee pain and any degree of disability, $7.5 \%$ had $x$ ray changes of osteoarthritis in the knee as well (table 4).

If an HAQ cut off score of two or more is used to define severe disability, the Bristol estimates are remarkably similar to figures derived from the north of England study. This is likely to reflect the strong association of radiographic change with age and with disability, so that the subgroup of older people with knee pain who report severe disability are highly likely to have radiographic osteoarthritis as well. The importance of this is that crude estimates of the prevalence of severe knee osteoarthritis can be based on self reported pain and disability alone.

THE PREVALENCE STAIRCASE

The estimates from the preceding sections can be used to construct a staircase summarising the expected prevalence of knee pain and disability in a population of older adults and the proportion within each level with radiographic features of osteoarthritis (fig 1).

The categories in the staircase are inclusive. An additional separate subcategory is the estimated 1200 people with radiographic osteoarthritis but no pain.

INCIDENCE OF KNEE OSTEOARTHRITIS

In the Chingford Study, approximately $13 \%$ of women aged between 45 and 65 developed

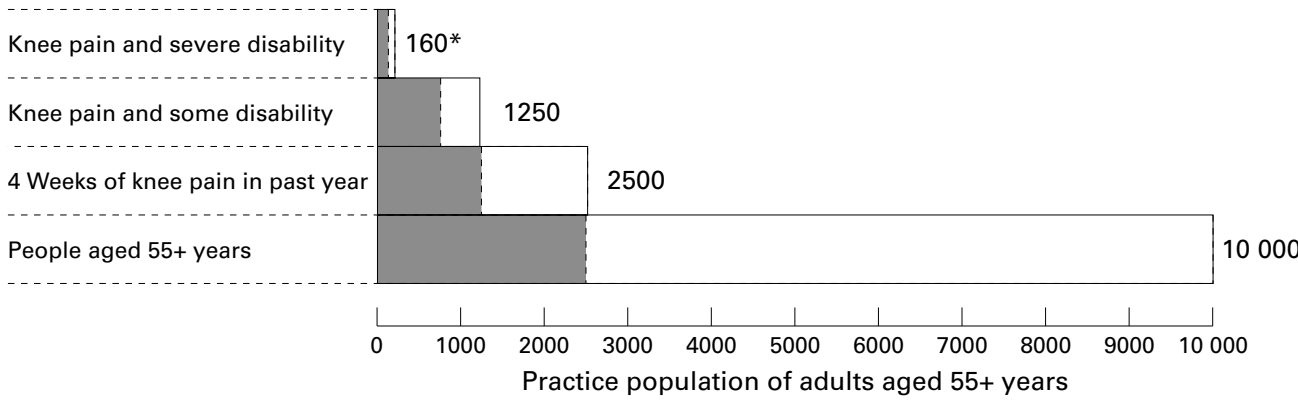

Figure 1 The prevalence staircase. Shading represents the proportion in each category with radiographic evidence of knee osteoarthritis. ${ }^{\star}$ The proportion with radiographic evidence in this category is not known, though seems likely to be high. incident radiographic evidence of knee osteoarthritis over a four year follow up. ${ }^{34}$ The Framingham Study of an older sample of men and women, followed up over eight years, found $15.6 \%$ developed incident radiographic osteoarthritis. ${ }^{18}$ Neither of these studies reported levels of pain or disability, though another analysis of the Framingham data suggested that fewer than one in four cases of incident radiographic osteoarthritis was associated with symptoms. ${ }^{35}$

Cumulative annual incidence could provide a useful estimate of the likely additional burden in the future. This assumes that the healthcare needs of people with current prevalent knee pain and osteoarthritis are met and that primary healthcare needs associated with incident cases are similar to prevalent cases. However, demand for health care may more reasonably be based on the rate at which cases manifest as presentations to the health services. section.

\section{SUMMARY OF COMMUNITY BURDEN}

- About one quarter of people over the age of 55 will report a significant episode of knee pain in the past year. Approximately half of these report some associated disability.

- Painful, severely disabling radiographic knee osteoarthritis affects about $1.5 \%$ of adults over the age of 55 . This proportion is higher in the older age categories. Painful knee osteoarthritis associated with mild to moderate disability affects up to $10 \%$ of adults aged over 55 .

\section{Primary care consultations for symptomatic knee osteoarthritis SEARCH STRATEGY}

The strategy described earlier was extended to include primary care consultations and referral rates. Official statistics from the United Kingdom were also used. ${ }^{2}$

PREVALENCE OF PRIMARY CARE CONSULTATIONS "Prevalence" in relation to consultations with primary care professionals is taken here to This will be considered in the following 
mean "the proportion of the registered practice population who consult at least once for a condition such as knee osteoarthritis during a specified period of observation". This contrasts with incidence, which is dealt with in a later section, and which is taken here to refer to "the frequency of first ever consultation for that condition".

From UK figures, $10 \%$ of registered $65-74$ year olds consult their doctor about osteoarthritis in the course of one year, half of them with chronic problems. ${ }^{2}$ This figure rises to $14 \%$ of over 85 year olds, but is lower below 65 years. The knee is not identified separately in these figures, and such data refer to "osteoarthritis as diagnosed by the general practitioner", which is likely to be a mixture of "pain thought to be osteoarthritis" and radiographically confirmed osteoarthritis.

A prospective case review by the Primary Care Rheumatology Society, a network of UK general practitioners with a specific interest in musculoskeletal problems, found that $40 \%$ of subjects consulting their general practitioners about osteoarthritis had problems with the knee (Dickson J, personal communication). When this figure is applied to the data above, the estimate is that $4 \%$ of the older population consult their general practitioners at least once in the course of a year because of knee osteoarthritis, of whom half ( $2 \%$ of the older population) are consulting for the first time or with an acute flare up of the problem.

Parallel figures from a population sample come from the Rotterdam Study of disability in people older than 55 years, which used radiographs, symptoms, and self reported consultations in a random population sample. ${ }^{36}$ The proportion of this older community sample who reported current pain in the hip or knee for which they had consulted their general practitioner and which had been given a label of "arthritis, rheumatism, wear and tear, or aging" was $15 \%$, with just under half $(6.2 \%$ of the whole sample) having $x$ ray evidence of knee osteoarthritis as well.

In the north of England population study, ${ }^{32}$ most of those identified as having severe pain and disability ( $8 \%$ of adults over 55 years) reported that they had seen their general practitioner within the previous year and been told at some time that they had arthritis. These figures are compatible with the estimate of $4.8 \%$ of the Dutch population who consult their general practitioner about knee pain each year-a figure based on general practice records rather than patient recall. ${ }^{37}$ Specific figures on primary care are not available from America, but of the 46 million patient visits to doctors in that country each year that are attributed to osteoarthritis, knee osteoarthritis is the most common presentation. ${ }^{38}$

INCIDENCE OF PRIMARY CARE CONSULTATIONS Figures from a prospective case review of general practitioner consultations estimated that approximately half of patients consulting for knee osteoarthritis were consulting for the first time or with an acute flare up of the problem $-2 \%$ of the older population (Dickson J, personal communication). A study of a health maintenance organisation population in America suggested an overall annual incidence of 2.4 per 1000 registered population for first consultation with definite radiographic knee osteoarthritis and accompanying pain, rising to 10 per 1000 in women aged $70-89 .^{39}$ In a one year prospective study of physician visits in rural Finland the incidence of confirmed symptomatic knee osteoarthritis was 6 per $1000 .{ }^{40}$ In a population based cohort from Rochester, USA, the incidence of new consultations with hospital based physicians in 60-79 year olds for symptomatic radiographic knee osteoarthritis was 10 per 100 per year. ${ }^{41}$ This latter figure represents a mix of what in the UK and the Netherlands would be primary care (initial contact) and secondary care (specialist contact). However, if it is assumed that all these figures represent confirmed radiographic osteoarthritis and first ever presentations, then they are consistent with estimates from Britain.

THE PRIMARY CARE CONSULTATION STAIRCASE Across Europe, consultation figures will vary with the referral system, because in some countries specialists will, as in the USA, be accessed directly rather than through the family practitioner. However, if it is assumed that the total figures for those seeking health care for symptomatic knee osteoarthritis do not vary greatly across different countries, a very crude estimate would be that $1.5 \%$ of the elderly population over 55 years (proportionately more in those over 75 years) consult with severely painful and disabling osteoarthritis of the knee in the course of any one year, $1.5 \%$ consult with less disabling chronic knee pain, and $1.0 \%$ consult their primary care practitioner with knee symptoms for the first time (fig 2).

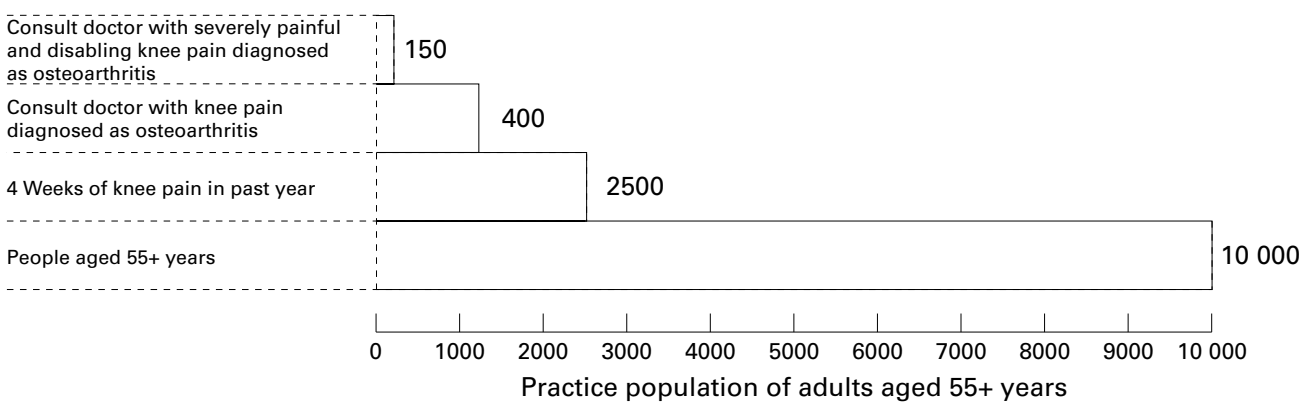

Figure 2 The consultation prevalence staircase. 
SUMMARY OF PRIMARY CARE CONSULTATIONS

- Among adults over 55 years, one in six people with knee pain consult their doctor in the course of one year. Around one third of these have severe pain and disability.

- The annual incidence of consultations for symptomatic knee osteoarthritis is estimated to be $0.5 \%$ overall of those over 55 years, rising to $1 \%$ in those over 70 years.

\section{Conclusion}

The review has brought together published population prevalence estimates of pain, disability, and radiographic changes in older adults with knee pain, to provide a basic description of the potential burden of knee osteoarthritis in the community. Because most studies do not examine all three aspects together, the estimates that we have generated from a review of available high quality studies remain relatively crude. In addition, we considered the current use of health care in relation to this burden, concluding that severely disabling knee pain represents a minority of all knee pain presenting to primary health care in any one year. Given the range of potentially effective primary care treatments available for sufferers, ${ }^{4}$ it is important that the focus of primary care for osteoarthritis should not be limited to those with radiographic disease or to those with severely disabling symptoms who are candidates for joint replacement. ${ }^{42}$

Much disabling knee pain in older patients in primary care may not represent radiographically defined osteoarthritis. However, nonsurgical treatments are likely to exert their effects on pain and disability regardless of the presence of radiographic changes and so it can be argued that a radiographic diagnosis of osteoarthritis is not required in order to start treatment in new consulters. However, there is an absence of empirical evidence about this. The concordance between clinical and radiographic findings may eventually improve because of developments in imaging, such as the systematic inclusion of the patellofemoral joint in grading systems. ${ }^{43} 44$ In the meantime it seems reasonable to consider the basic case definition in relation to the need and demand for primary health care as being one of knee joint pain and disability in older people.

There are some issues for future research. Firstly, it is important to establish whether those people with knee pain who do not consult in any one year (the majority) have significant needs which health care could meet effectively. Secondly, the effectiveness of primary care treatments needs to be established as judged by their long term impact in reducing the community burden of pain and disability and the need for surgery. This is particularly important given likely future rise in demand for joint replacement. ${ }^{45}$ Thirdly, clear criteria for referral to secondary care need to be tested for effectiveness in primary care.

We have presented "staircase" figures to illustrate the burden of clinical and radiographic osteoarthritis in the community and current use of primary care. Such estimates, together with effectiveness studies, can form the basis for assessing the need and demand for primary health care for this condition. However, such estimates need to be adapted for different healthcare systems and to changing or more detailed evidence of the short and long term effectiveness of primary care treatments.

This review was supported in part by an educational grant from Johnson and Johnson, as part of the Renovare initiative. We thank Professor Paul Dieppe and Professor Stefan Lohmander thank their helpful comments.

Appendix: Medline search strategy

1 knee.ti or knee.ab

2 osteoarthritis.ti or osteoarthritis.ab

3 OA.ti or OA.ab

4 osteoarthrosis.ti or osteoarthrosis.ab

5 gonarthrosis.ti or gonarthrosis.ab

6 disability.ti or disability.ab

7 pain.ti or pain.ab

82 or 3 or 4 or 5 or 6 or 7

98 and 1

10 outcome.ti or outcome.ab

11 epidemiology.ti or epidemiology.ab

12 primary care.ti or primary care.ab

13 family practice.ti or family practice.ab

14 general practice.ti or general practice.ab

15 population.ti or population.ab

16 incidence.ti or incidence.ab

17 consultation.ti or consultation.ab

18 prevalence.ti or prevalence.ab

1910 or 11 or 12 or 13 or 14 or 15 or 16 or 17 or 18

2019 and 9

1 Stevens A, Raftery J, eds. Health care needs assessment. Vol 1 The epidemiologically based needs assessment reviews. Oxford: Radcliffe Medical Press, 1994

2 Royal College of General Practitioners. Morbidity statistics from general practice 1991-92. London: HMSO, 1995

3 Martin J, Meltzer H, Elliot D. OPCS surveys of disability in Great Britain. Report 1. The prevalence of disability among adults. Office of Population Censuses and Surveys, Social Survey Division. London: HMSO, 1988.

4 Lane NE, Thompson JM. Management of osteoarthritis in the primary-care setting: an evidence-based approach to treatment. Am J Med 1997;103:25-30S.

5 Felson DT, Naimark A, Anderson J, Kazis L, Castelli W, Felson DT, Naimark A, Anderson J, Kazis L, Castelli W,
Meenan RF. The prevalence of knee osteoarthritis in the Meenan RF. The prevalence of knee osteoarthritis in the
elderly. The Framingham Osteoarthritis Study. Arthritis elderly. The Framingham

6 Van Saase JLCM, van Romunde LKJ, Cats A, Vandenbroucke JP, Valkenburg HA. Epidemiology of osteoarthritis: Zoetermeer survey. Comparison of radioogical osteoarthritis in a Dutch population with that in 10 other populations. Ann Rheum Dis 1989;48:271-80.

7 Claessens AAMC, Schouten JSAG, van den Ouweland FA, Valkenburg HA. Do clinical findings associate with radiographic osteoarthritis of the knee? Ann Rheum Dis 1990;49:771-4.

8 Spector TD, Hart DJ, Leedham-Green M. The prevalence of knee and hand osteoarthritis in the general population [abstract]. Arthritis Rheum 1991;34(suppl):S171.

9 Odding E, Valkenburg A, Algra D, Vandenouweland FA, Grobbee DE, Hofman A. Associations of radiological osteoarthritis of the hip and knee with locomotor disability in the arthritis of the hip and knee with locomotor disability

10 McAlindon TE, Snow S, Cooper C, Dieppe PA. Radiographic patterns of osteoarthritis of the knee joint in the community: the importance of the patellofemoral joint. Ann Rheum Dis 1992;51:844-9.

11 Altman R, Asch E, Bloch D, Bole G, Borenstein D, Brandt $\mathrm{K}$, et al. Development of criteria for the classification and reporting of osteoarthritis. Classification of osteoarthritis of the knee. Arthritis Rheum 1986;29:1039-49.

12 Hochberg MC, Altman RD, Brandt KD, Clark BM, Dieppe PA, Griffin MR, et al. Guidelines for the medical management of osteoarthritis. Part II. Osteoarthritis of the knee. Arthritis Rheum 1995;38:1541-6.

13 McAlindon T, Dieppe P. Osteoarthritis: definitions and criteria. Ann Rheum Dis 1989;48:531-2.

14 McAlindon TE. The knee. In: Croft P, Brooks PM, eds. Regional musculoskeletal pain. Clin Rheumatol 1999;13: 329-44.

15 Mazzuca SA, Brandt KD, Katz BP, Dittus S, Freund DA, Lubitz R, et al. Comparison of general internists, family physicians, and rheumatologists managing patients with symptoms of osteoarthritis of the knee. Arthritis Care Research 1997;10:289-99. 
16 Dieppe PA, Cushnaghan J, Shepstone L. The Bristol 'OA500' Study: progression of osteoarthritis (OA) over 3
years and the relationship between clinical and radioyears and the relationship between clinical and radiographic changes

17 The Primary Care Rheumatology Society. The management of osteoarthritis. Guidelines 1999;8:301-3.

18 Felson DT, Zhang Y, Hannan MT, Naimark A, Weissman B, Aliabadi $\mathrm{P}$, et al. Risk factors for incident radiographic knee osteoarthritis in the elderly. The Framingham Study. Arthritis Rheum 1997;40:728-33.

19 McAlindon TE, Cooper C, Kirwan JR, Dieppe PA. Knee pain and disability in the community. $\mathrm{Br} \mathrm{J}$ Rheumatol 1992;31:189-92.

20 O'Reilly SC, Muir KR, Doherty M. Screening for pain in knee osteo

21 Urwin M, Symmons D, Allison T, Brammah T, Busby $\mathrm{H}$ Roxby M, et al. Estimating the burden of musculoskeletal disorders in the community: the comparative prevalence of disorders in the community: the comparative prevalence of symptoms at different anatomical sites, and the relation
social deprivation. Ann Rheum Dis 1998;57:649-55.

22 Badley EM, Tennant A. Changing profile of joint disorders with age: findings from a postal survey of the population of Calderdale, West Yorkshire, United Kingdom. Ann Rheum Dis 1992;51:366-71.

23 Anderson JJ, Felson DT. Factors associated with osteoarthritis of the knee in the first national health and nutrition examination survey (HANES 1). Evidence for an association with overweight, race and physical demands of work Am J Epidemiol 1988;128:179-89.

24 Lethbridge-Cejku M, Scott WW Jr, Reichle R, Ettinger WH, Zonderman A, Costa P, et al. Association of radiographic features of osteoarthritis of the knee with knee pain: data from the Baltimore Longitudinal Study of Aging. Arthritis Care Research 1995;8:182-8.

25 McCarney R, Croft P. Knee pain. In: Crombie IK, Croft PR, Linton SJ, LeResche L, von Korff M, eds. Epidemiology PR, Linton SJ, LeResche L, von K

26 Woo J, Ho SC, Lau J, Leung PC. Musculoskeletal complaints and associated consequences in elderly Chinese complaints and associated consequences in elderly Chinese

27 Bergstrom G, Bjelle A, Sundh V, Svanborg A. Joint disorders at ages 70,75 and 79 years - a cross-sectional comparison Br J Rheumatol 1986;25:333-41.

28 Anderson S, Winckler F. The epidemiology of primary osteoarthritis of the knee in Greenland. Arch Orthop Trauma Surg 1979;93:91-4.

29 Zhang N, Shi Q, Zhang X. An epidemiological study of knee osteoarthritis. Chinese Journal of Internal Medicine 1995; 34:84-7.

30 Jordan JM, Linder GF, Renner JB, Fryer JG. The impact of arthritis in rural populations. Arthritis Care Research 1995;8:242-50.
31 Sun Y, Gunther KP, Brenner H. Reliability of radiography grading of osteoarthritis of the hip and knee. Scand J grading of osteoarthritis of

32 Tennant A, Fear J, Pickering A, Hillman M, Cutts A, Chamberlain MA. Prevalence of knee problems in the population aged 55 years and over: identifying the need for arthroplasty. BMJ 1995; 310:1291-3.

33 Lequesne MG. The algofunctional indices for hip and knee osteoarthritis. J Rheumatol 1997;24:779-81.

34 Hart DJ, Doyle DV, Spector TD. Incidence and risk factors for radiographic knee osteoarthritis in middle-aged women. The Chingford Study. Arthritis Rheum 1999;42: 17-24.

35 McAlindon TE, Wilson PWF, Aliabadi P, Weissman B, Felson DT. Level of physical activity and the risk of radiographic and symptomatic knee osteoarthritis in the elderly: the Framingham Study. Am J Med 1999;106:151-7.

36 Odding E, Valkenburg HA, Algra D, Vandenouweland FA, Grobbee DE, Hofman A. The association of abnormalities on physical examination of the hip and knee with locomotor disability in the Rotterdam Study. Br J Rheumatol 1996;35:884-90.

37 Roland M, Jamoulle M. "Doctor, my knee hurts . ..", the generalist's point of view. Rev Med Brux 1997;18:294-300.

38 Abyad A, Boyer JT. Arthritis and aging. Curr Opin Rheumatol 1992;4:153-9.

39 Oliveria SA, Felson DT, Reed JI, Cirillo PA, Walker AM. Incidence of symptomatic hand, hip, and knee osteoarthritis among patients in a health maintenance organization. Arthritis Rheum 1995;38:1134-41.

40 Kannus P, Jarvinen M, Kontiala H, Bergius L, Hyssy E, Salminen E, et al. Occurrence of symptomatic knee Salminen E, et al. Occurrence of symptomatic knee study. Ann Rheum Dis 1987;46:804-8.

41 Wilson MG, Michet CJ Jr, Ilstrup DM, Melton LJ III. Idiopathic symptomatic osteoarthritis of the hip and knee: a population-based incidence study. Mayo Clin Proc 1990; 65:1214-21.

42 Dieppe P. Osteoarthritis: time to shift the paradigm. BMJ 1999;318:1299-300.

43 McAlindon TE, LaValley M, Zhang Y, Hannan MT, Felson DT. Does chronologic information improve concordance between knee pain and radiographic knee osteoarthritis? Arthritis Rheum 1996;39(suppl 9):S299.

44 Lanyon P, O'Reilly S, Jones A, Doherty M. Radiographic assessment of symptomatic knee osteoarthritis in the community: definitions and normal joint space. Ann Rheum Dis 1998;57:595-601.

45 Birrell F, Johnell O, Silman A. Projecting the need for hip replacement over the next three decades: influence of changing demography and threshold for surgery. Ann Rheum Dis 1999;58:569-72. 